\title{
Geographical distribution of shear wave anisotropy within marine sediments in the northwestern Pacific
}

Takashi Tonegawa ${ }^{1 *}$, Yoshio Fukao ${ }^{1}$, Gou Fujie', Shunsuke Takemura ${ }^{2,3}$, Tsutomu Takahashi $^{1}$ and Shuichi Kodaira ${ }^{1}$

\begin{abstract}
In the northwestern Pacific, the elastic properties of marine sediments, including $P$-wave velocities $(V p)$ and $S$ wave velocities $(V s)$, have recently been constrained by active seismic surveys. However, information on $S$ anisotropy associated with the alignments of fractures and fabric remains elusive. To obtain such information, we used ambient noise records observed by ocean-bottom seismometers at 254 sites in the northwestern Pacific to calculate the auto-correlation functions for the $S$ reflection retrieval from the top of the basement. For these $S$ reflections, we measured differential travel times and polarized directions to reveal the potential geographical systematic distribution of $S$ anisotropy. As a result, the observed differential times between fast and slow axes were at most $0.05 \mathrm{~s}$. The fast polarization axes tend to align in the trench-parallel direction in the outer rise region. In particular, their directions changed systematically in accordance with the direction of the trench axis, which changes sharply across the junction of the Kuril and Japan trenches. We consider that a contributing factor for the obtained $S$ anisotropy within marine sediments in the outer rise region is primarily aligned fractures due to the tensional stresses associated with the bending of the Pacific Plate. Moreover, numerical simulations conducted by using the three-dimensional (3D) finite difference method for isotropic and anisotropic media indicates that the successful extraction of $S$ anisotropic information from the $S$ reflection observed in this study is obtained from nearvertically propagating $S$ waves due to extremely low $V s$ within marine sediments. In addition, we conducted an additional numerical simulation with a realistic velocity model to confirm whether $S$ reflections below the basement can be extracted or not. The resultant auto-correlation function shows only $S$ reflections from the top of the basement. It appears that such near-vertically propagating $S$ waves obscure $S$ reflections from interfaces below the basement.
\end{abstract}

Keywords: Ambient noise; Ocean-bottom seismometer; Shear wave reflection; Shear wave anisotropy; Northwestern Pacific

\section{Background}

Seismic information of marine sediments is important for understanding their historical development as well as for performing seismological techniques including travel time corrections for imaging underlying structure and for the determination of hypocenter locations. The Pacific Plate in the northwestern Pacific is one of the best seismically characterized oceanic plates (e.g., Kodaira et al.,

\footnotetext{
* Correspondence: tonegawa@jamstec.go.jp

'Research and Development Center for Earthquake and Tsunami, Japan Agency for Marine-Earth Science and Technology, 3173-25, Showa-machi, Kanazawa-ku, Yokohama 236-0001, Japan

Full list of author information is available at the end of the article
}

2014). Constraints of the $P$-wave velocity $(V p)$ structure at the shallow part of the plate have been accomplished by seismic refraction and reflection surveys focusing on structures beneath the seawater (Cadet et al., 1987; Shimamura et al. 1983; Fujiwara et al., 2007; Shinohara et al. 2008). $S$ wave velocity $(V s)$ structures have also been well confined, particularly at depths shallower than the topmost of the oceanic mantle by active seismic surveys (Fujie et al., 2013). At greater depths, surface wave (Isse et al., 2009) and receiver function (Kawakatsu et al., 2009; Kumar et al. 2011) analyses have revealed $V s$ structure beneath the ocean.

\section{包 Springer}

(C) 2015 Tonegawa et al. Open Access This article is distributed under the terms of the Creative Commons Attribution 4.0 International License (http://creativecommons.org/licenses/by/4.0/), which permits unrestricted use, distribution, and reproduction in any medium, provided you give appropriate credit to the original author(s) and the source, provide a link to the Creative Commons license, and indicate if changes were made. 
Despite the soft materials, it has been shown that the elastic properties of marine sediments have anisotropic structures by using signals from active seismic sources in the Nankai Subduction Zone, Japan (Tsuji et al. 2011). Such an anisotropic structure is potentially indicative of the existence of aligned cracks or fractures associated with the stress field at local or regional scales. When compressional stress is applied to a medium, cracks open under certain conditions with their major (long) axes aligned along the direction of compression. The fast polarization direction is taken to be the direction of the major axis in the case of ellipsoidal cracks (e.g., Hudson 1981). Thus, in addition to the fact that $V s$ is extremely sensitive to the presence of fractures, fluids, and hydrous minerals within a medium, because anisotropic parameters are key to understanding the alignments of cracks beneath the seafloor structure, more detailed material information within marine sediments could be obtained by combining these elastic parameters with $V p$ profiles and reflection images. It is therefore useful to construct a method to obtain $V s$ and its anisotropic information within marine sediments by using ocean-bottom seismometer (OBS) records.

Ambient noise correlation is capable of detecting surface (Campillo and Paul 2003; Shapiro and Campillo 2004), body (Roux et al. 2005; Miyazawa et al. 2008; Boué et al. 2013; Nakata et al. 2015), and reflected (Draganov et al. 2007, 2009; Zhan et al. 2010; Ryberg 2011; Poli et al. 2012a, 2012b; Ruigrok et al. 2012; Tibuleac and von Seggern 2012) waves propagating within a background wavefield. Tonegawa et al. (2013) calculated auto-correlation functions (ACFs) by using ambient noise at $1-3 \mathrm{~Hz}$ recorded by three broadband OBSs deployed on the outer rise region in the northwestern Pacific. The ACFs successfully showed $S$ reflection retrieval from the basement and an $S$ anisotropy of $2 \%$ within marine sediments from differential travel times of the $S$ reflections polarized in various directions. However, the result relevant to $S$ anisotropy was determined from only one OBS site among the three; one of the remaining two sites represented relatively weak $S$ anisotropy $(<0.5 \%)$ and the other one showed no $S$ reflections. It is thus necessary to confirm whether the features reported by Tonegawa et al. (2013) are ubiquitous in the northwestern Pacific.

In this paper, we investigate $S$ reflection retrieval by using continuous records observed at 254 OBS sites extending over an area of $500 \times 500 \mathrm{~km}^{2}$ in the northwestern Pacific (Fig. 1) and also investigate features related to $S$ anisotropy within marine sediments, including its degree and fast polarization direction. Moreover, by conducting threedimensional (3D) numerical simulations with finite difference methods, we verify what kind of environment causes bias for the estimation of anisotropic parameters. Further, we compare the retrieval of $S$ reflection between our observation and synthetic waveforms obtained by using a realistic velocity model. Finally, we interpret the potential causes of observed anisotropy within marine sediments.

\section{Methods}

Deploying three-component, short-period $(4.5 \mathrm{~Hz})$ sensors with a station spacing of $6 \mathrm{~km}$, we constructed six linear OBS arrays in the northwestern Pacific for seismic exploration surveys during 2009 and 2010 (Fujie et al. 2013). The observation period for each OBS was between 1 and

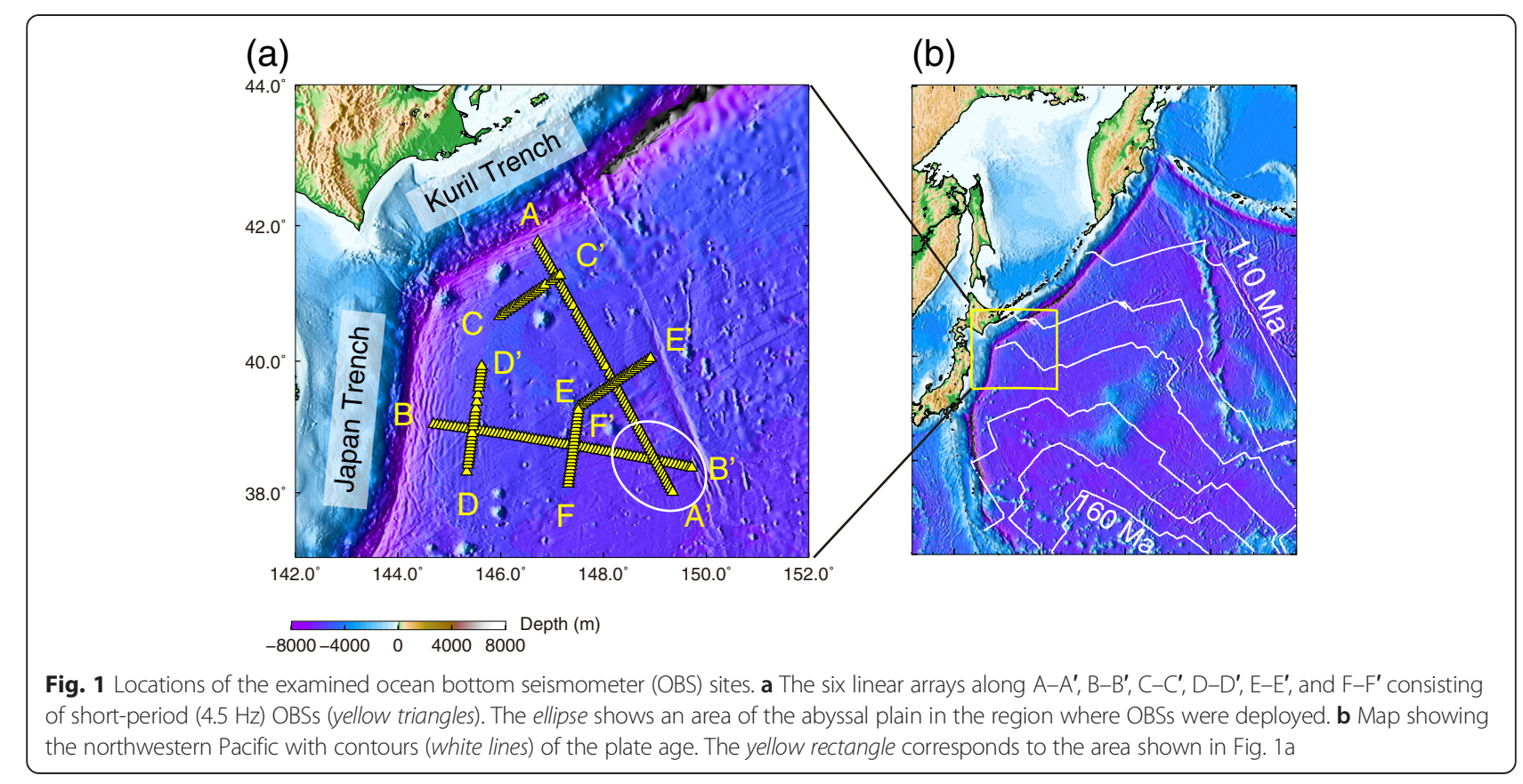


2 weeks. The continuous record for each OBS was dominated mainly by signals of air gun shots, but ambient noise without shot signals was also recorded with a time length of at least 1 day. This allowed us to use the record for ambient noise analysis for each OBS site. The six linear arrays thus totally provided a total of 254 sites with a 1-day ambient noise record. The horizontal direction of each OBS could be estimated by using air gun shot signals, because the locations of the shots and the OBSs were well constrained. In the case that the horizontal direction could not be estimated owing to the fewer available number of the shot signals with good signal-to-noise ratio $(S / N)$, we did not use records observed by such OBSs, resulting in 201 available OBS sites.

The processing for $S$ reflection retrieval from the OBS records was identical to that reported in previous research (Tonegawa et al. 2013) except for the frequency range used. We applied a band-pass filter of $2-5 \mathrm{~Hz}$ to the continuous records of two horizontal components. We then synthesized ambient noise records for each azimuth by rotating the two horizontal components at $5^{\circ}$ increments, removed energetic seismic signals, calculated ACFs from continuous records with a time length of $600 \mathrm{~s}$, and stacked the ACFs over the course of 1 day. Tonegawa et al. (2013) reported that the travel time of $S$ reflection emerged in the ACF was stable when using a continuous record for 1 day. The rotation angle was measured clockwise from the north. The ACFs of ambient noise rotated for all directions allowed us to extract $S$ reflections with various polarization directions.

To examine the differential travel times of $S$ reflections polarized into various directions, we first calculated a reference waveform by stacking the ACFs over all of the rotated directions. We then cross-correlated the stacked $S$ reflection in the waveform with those of every 1-day stacked ACF at every rotated direction. The same time window was adopted for both the reference waveform and each ACF trace: 1-2 s around the $S$ reflection, as shown by the red dots in Fig. 2a. This time window was selected by roughly hand-picking the start and end times of the $S$ reflection. ACF traces without red dots in Fig. 2b were not used in this study because of unclear $S$ reflections. Similarly, we estimated differential travel times and fast polarization directions for other linear arrays. The degree of $S$ anisotropy was estimated by dividing the differential travel times of the $S$ reflection between fast and slow axes by the absolute travel time of the $S$ reflection. We considered the lag time of the negative peak of the $S$ reflection that emerged in the reference waveform as the absolute travel time.

\section{Results}

$S$ reflection retrieval in the northwestern Pacific

Figure 2a shows the ACFs obtained by using the northsouth (NS) component along line $\mathrm{A}-\mathrm{A}^{\prime}$; we did not display ACFs at OBSs for which the horizontal direction could not be estimated. The ACFs show large amplitudes with negative polarities at a lag time of 2-6 s; the right (left) direction indicates positive (negative) polarity in the figure. Because such features are consistent with those obtained in the previous research (Tonegawa et al. 2013), these signals would correspond to the $S$ reflection from the basement. The obtained lag time of the $S$ reflection in the ACFs corresponds to the two-way travel time of an $S$ wave propagating between the seafloor and basement. An additional phase with weak amplitude at a lag time of 4-12 s in the ACFs is the first-order multiple reflection. $S$ reflections from other interfaces related to the crust and mantle cannot be observed in the ACFs.

Impulse-like reflections can be traced in the northern part of line A-A' $(x<350 \mathrm{~km})$, whereas $S$ reflections in the southern part show multiple peaks, which is consistent with the seismic survey result. A post-stack time migration of multi-channel seismic (MCS) reflection survey data has been previously performed along A-A' (Fig. 2c) by Fujie et al. (2013). Fujie et al. (2013) reported that the sub-seafloor structure in the southern part $(x>350 \mathrm{~km})$ was formed near the spreading center and that the subseafloor structure around the region was deformed by magma-involved activity and normal faults during its formations. This explains the remarkably complex topography of the basement in the southern part, as shown in Fig. 2c, in addition to the multiple peaks of ACFs at the OBSs in the southern part (Fig. 2b).

Similar features can be identified along other lines; the ACFs along lines $C-C^{\prime}, D-D^{\prime}$, and $E-E^{\prime}$ almost all show single, negative peak $S$ reflections (Fig. 3b, c, and e). On the contrary, because the transect along line $F-F^{\prime}$ is likely to show multiple peaks of $S$ reflections, the structure around this region may be also affected by seafloor formation (Fig. 3d). Moreover, the features along line B-B' appear to be somewhat complicated. The ACFs show unclear $S$ reflections in the eastern part of line B-B' (Fig. 3a) and multiple peaks of $S$ reflections in the western part. To interpret the features of the emerged reflections in detail, it would be necessary to reveal the detailed structures from seismic surveys along line B-B'.

\section{$V p / V s$ within marine sediments}

The time migration result (Fujie et al. 2013) provides us information relevant to the two-way travel time of $P$-wave between the seafloor and basement. Using the two-way travel times of $P$ and $S$ reflections, we can estimate $V p / V s$ within the marine sediments. Given a $V p$ of $1.6 \mathrm{~km} / \mathrm{s}$ for marine sediments (Shinohara et al. 2008) and an air gun shot frequency range of $5-20 \mathrm{~Hz}$, as used by Fujie et al. (2013), the wavelengths of $P$-waves within the sediments are $80-320 \mathrm{~m}$. In the case of $S$ waves with an employed frequency range of $2-5 \mathrm{~Hz}$ and a $V s$ of $0.2 \mathrm{~km} / \mathrm{s}$ 


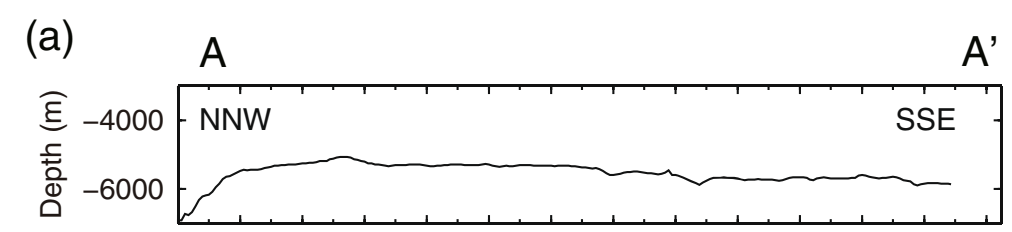

(b)

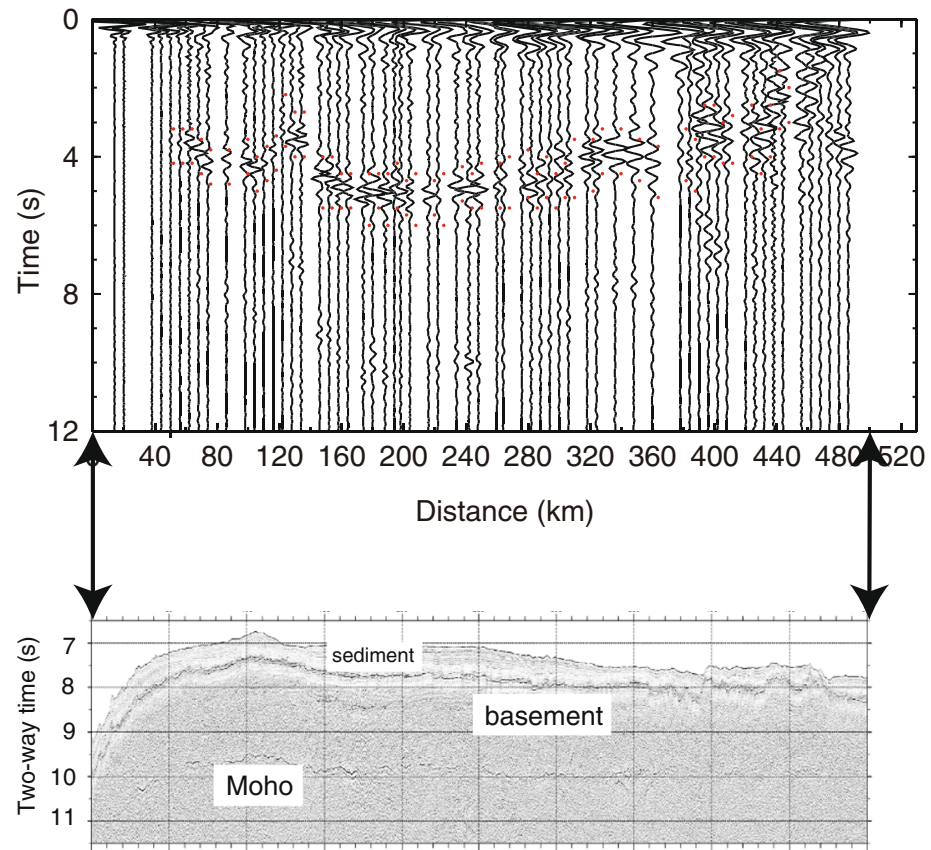

(d)

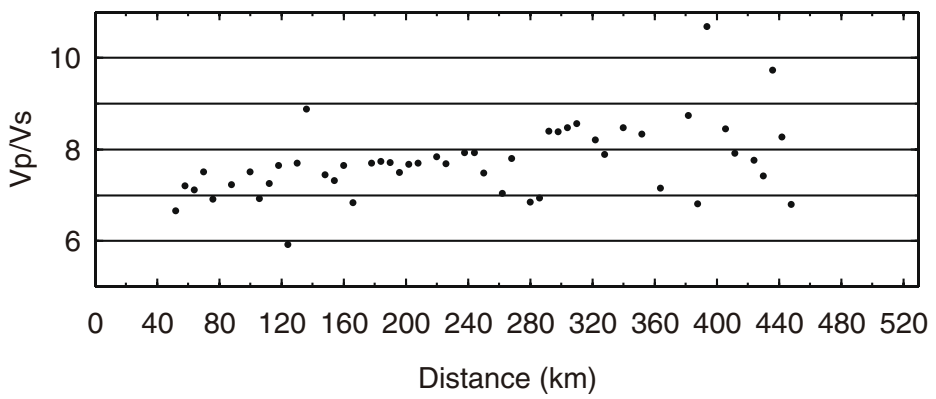

Fig. $2 \mathrm{~S}$ reflections that emerged in the auto correlation functions (ACFs) along $A-A^{\prime}$. a The bathymetry along $A-A^{\prime}$. b The $A C F$ transect along A-A'. Left/right direction corresponds to negative/positive polarity for the ACF. An ACF is plotted for each ocean-bottom seismometer (OBS) site. Red dots indicate the time window for searching anisotropic parameters, differential travel time and fast polarization direction. $\mathbf{c}$ Post-stack time migration of multi channel seismic (MCS) data along A-A' (after Fujie et al. 2013). d Vp/Vs along A-A'. The two-way travel time of $S$ reflections obtained in this study is divided by that of $P$ reflections from a seismic survey (after Fujie et al. 2013)

(Tonegawa et al. 2013), the wavelength becomes 40-100 m, indicating that estimation of $V p / V s$ within marine sediments can be performed with mostly comparable wavelengths between $P$ and $S$ waves. Figure $2 \mathrm{~d}$ shows the estimated value of $V p / V s$ for each OBS site. Although the $V p / V s$ is roughly concentrated around 8 , it appears that the value decreases gradually from 9 to 7 northward from the location of $x=350 \mathrm{~km}$. Because Fujie et al. (2013) found an increase of $V p / V s$ at the basement around the outer rise region, this may correspond to water infiltration downward from the sediment to the basement. However, it is also possible to consider that water trapped inside the sediments escapes upward due to its buoyancy through fractures formed around the outer rise region. In the southern part, the estimated $V p / V s$ may be unstable due to multiple peaks of $S$ reflections.

\section{S anisotropy within marine sediments}

The estimation of a fast axis at each OBS site is summarized in Fig. 4a. The length and direction of the yellow 


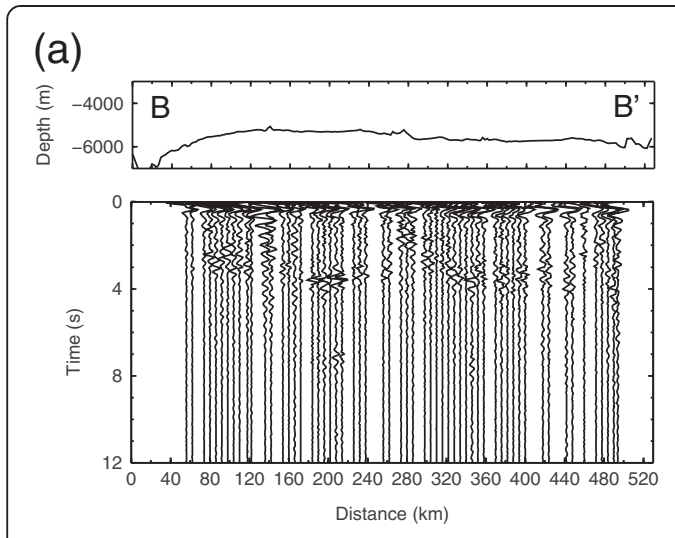

(b)

(c)
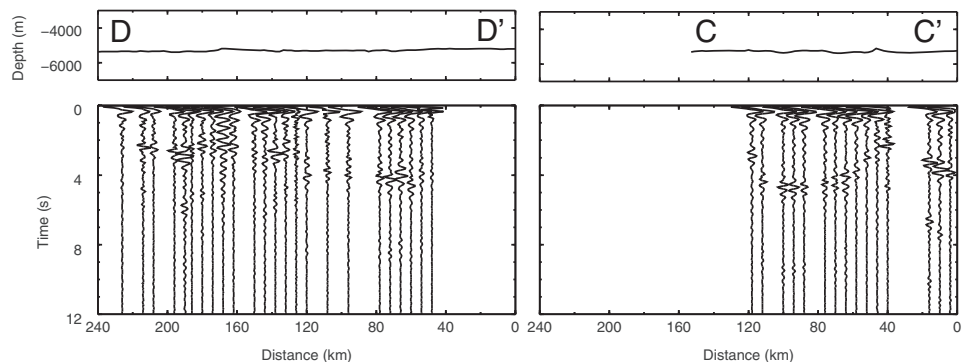

(d)

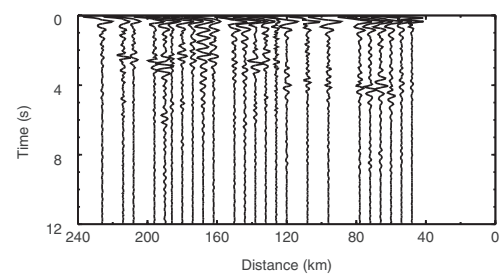

(e)
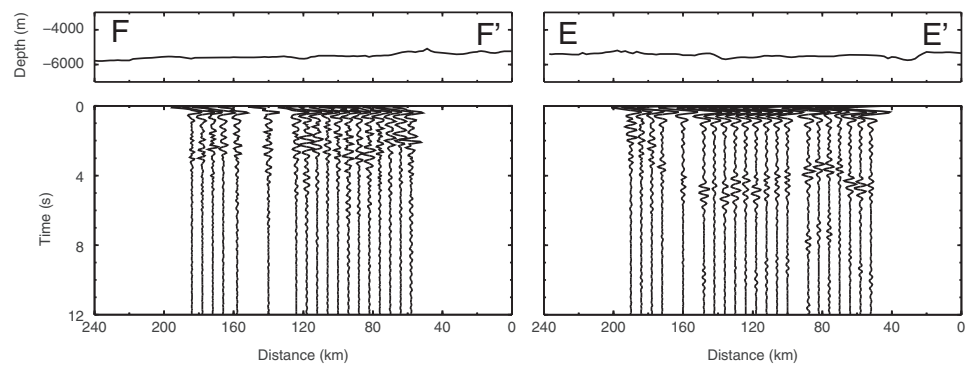

Fig. $3 \mathrm{~S}$ reflections that emerged in the auto correlation functions (ACFs) along five linear arrays. a-e Same as Fig. 2b but for lines B-B', C-C', D-D', $E-E^{\prime}$, and $F-F^{\prime}$

bar in the figure indicate the degree of $S$ anisotropy and its fast polarization direction. Herein, as shown in Fig. 4b, we define the following three regions: area $\mathrm{A}$, the region from the top of the outer rise to the trench; area B, the region between the top of the outer rise and just short of the abyssal plain; and area $\mathrm{C}$, the region of the abyssal plain where the bathymetry and basement are remarkably undulating. The most pronounced feature is that the fast axes are estimated to be in the trench-parallel direction in area A, except for the southern part of area $\mathrm{A}$, as will be subsequently discussed. On the contrary, the degree of anisotropy decreases abruptly in area B $(<0.5 \%)$, compared with that in area A $(1-2 \%)$. These features are in good agreement with those reported previously (Fig. 4a; Tonegawa et al. 2013). Moreover, it appears that the anisotropic characteristics are complex in area $C$, probably reflecting large lateral heterogeneities within the sediments in the abyssal plain.

We plotted a rose diagram (Fig. 4c, d) by using the yellow bars shown in box 1 in Fig. 4a. The degree of the anisotropy was averaged at each azimuth bin with an interval of $10^{\circ}$. The fast polarization direction in box 1 is estimated to be ENE-WSW, which is in good agreement with the direction of the Kuril Trench (denoted by the red arrows in Fig. 4c). The degree of the anisotropy was approximately $1.5 \%$. The rose diagram in box 2 shows an NS-trending fast axis with an anisotropy of $1 \%$ (denoted by the red arrows in Fig. 4d), the direction of which is parallel to the trench axis. Both diagrams show directions other than the trench-parallel. The rose diagram in box 1 shows a fast axis at $\mathrm{N} 30^{\circ} \mathrm{E}$ with an anisotropy of $1.5 \%$. The fast polarization direction in the rose diagram in box 2 shows several patterns, including fast axes at $\mathrm{N} 45^{\circ} \mathrm{E}$ and $\mathrm{N} 30^{\circ} \mathrm{E}$ with an anisotropy of 2-3 \% (denoted by blue and pale-blue triangles in Fig. 4d) and a NW-SE-trending fast axis with an anisotropy of $1 \%$ (denoted by the orange triangle in Fig. $4 \mathrm{~d}$ ). The features in box 2 can also be observed in the magnified map image in Fig. 4e.

\section{Discussion}

Numerical simulation for retrieving $S$ reflection

An understanding of the mechanism inducing the differential travel times of $S$ reflections polarized into various directions would be useful for interpretation of the obtained $S$ anisotropy. Herein, we performed numerical simulations to investigate $S$ reflection retrieval and the characteristics of their differential travel times with twolayered simple velocity models based on the following three cases: (1) a comparison of $S$ reflections from horizontal and dipping interfaces in a two-layered isotropic medium with evenly distributed sources, (2) $S$ reflection retrieval from a horizontal interface in anisotropic upper and isotropic lower layers with evenly distributed sources, and (3) $S$ reflection retrieval from a horizontal interface in anisotropic upper and isotropic lower layers with unevenly distributed sources.

The retrieval of reflections with passive sources has been previously examined by using numerical simulations, in which the sources were randomly distributed and 


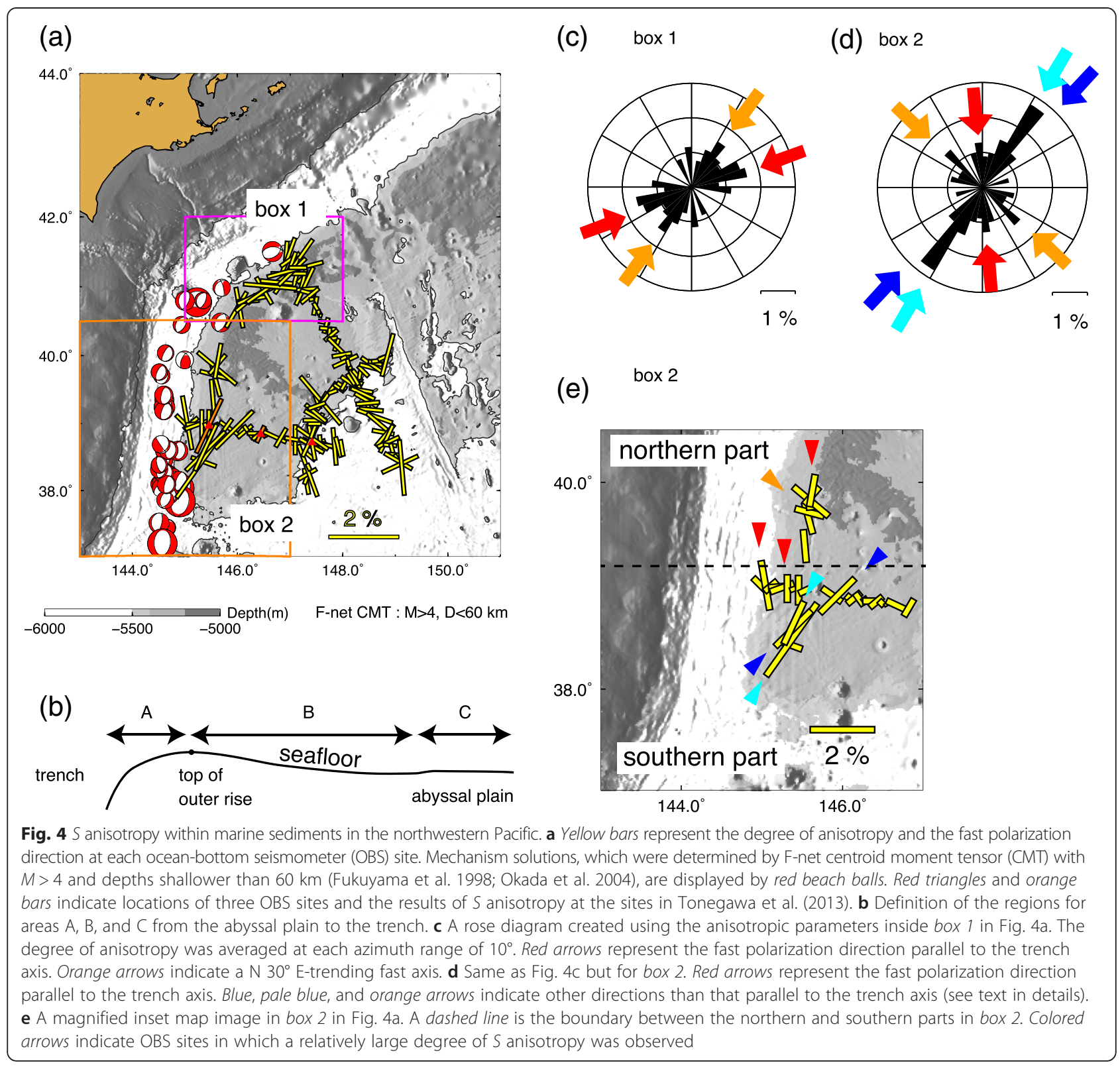

subsequently activated (e.g., Draganov et al. 2004; Thorbecke and Draganov 2011). Thorbecke and Draganov (2011) reported that the accuracy of retrieved reflections depends on several factors such as the duration and number of passive sources and the distribution and strength of the sources. Their findings indicate that careful considerations of the aforementioned source parameters should be required for the construction of accurate reflections. In addition, it is possible that the $S$ reflections observed in this study were excited by fluid disturbances such as wavewave interactions (Longuet-Higgins 1950) above the seafloor; this also requires careful parameterizations with regard to the source setting. In this study, we considered only ideal source parameterizations to mainly evaluate structural parameters affecting the differential travel times of $S$ reflections polarized into various directions and to reduce computational costs. Sources with the same strengths were evenly distributed below the seafloor, as is subsequently discussed.

We employed the 3D finite difference method based on rotated staggered grids with second-order calculation accuracies in time and space (Saenger 2000). The calculation was performed in the displacement-stress scheme with a time step of $0.005 \mathrm{~s}$. However, when more accurate information was required to evaluate travel time, we conducted the calculation with a time step of $0.001 \mathrm{~s}$. For such cases, we inserted the term $0.001 \mathrm{~s}$ after the obtained time. We calculated wavefields for anisotropic 
media by incorporating a maximum of 21 elastic constants. The model space $(x-y-z)$ was $16 \times 16 \times 12 \mathrm{~km}^{3}$, which includes two layers with a grid spacing of $0.05 \mathrm{~km}$ (Fig. 5a). The physical parameters of the model are summarized in Table 1. Because this simulation explores only the characteristics of $S$ reflections under various conditions, the model parameters represent a simplified two-layered submarine structure including the sediment and crust but do not correspond to a realistic structure. The location of the station was set at $(x, y, z)=(8,8,0)$. We simultaneously applied horizontal forces with a Ricker wavelet at a center frequency of $0.71 \mathrm{~Hz}$ with a maximum frequency of $1.02 \mathrm{~Hz}$ to 2337 locations, as indicated by the red dots in Fig. 5b. To make a wave incidence to the station with various azimuths and slownesses, sources should be located along a hemisphere beneath the station. These locations were randomly determined from grids, of which the distances to the station are between 7.95 and $8.05 \mathrm{~km}$ and at a vertically downward angle at the station of less than $45^{\circ}$. This resulted in a depth range of sources from 5.60 to $8.05 \mathrm{~km}$ (Fig. 5c). Herein, the direction of the horizontal source is the same as that of the horizontal component at the
Table 1 Velocity model for numerical simulation

\begin{tabular}{cccccc}
\hline & $H(\mathrm{~km})$ & $V p(\mathrm{~km} / \mathrm{s})$ & $V_{s}(\mathrm{~km} / \mathrm{s})$ & $V_{p} / V_{s}$ & $\rho\left(\mathrm{g} / \mathrm{cm}^{3}\right)$ \\
\hline Layer 1 & 2.00 & 2.00 & 1.00 & 2.00 & 2.60 \\
Layer 2 & 10.0 & 6.00 & 3.47 & 1.73 & 2.60 \\
\hline
\end{tabular}

station, and the forcing direction is rotated from $0^{\circ}$ to $180^{\circ}$ with an interval of $\theta=10^{\circ}$ (Fig. 5d). Therefore, we conducted a total of 19 calculations for different directions of the source and horizontal component. In the case of the distribution and forcing direction of sources used in this study, the ACF calculated by using the wavefields from 2337 simultaneously excited sources is equivalent to a function stacking 2337 ACFs using the wavefield from one source, which enabled us to reduce the calculation times from $2337 \times 19$ to $1 \times 19$. Because the minimum velocity is $1.0 \mathrm{~km} / \mathrm{s}$, the simulation could be conducted under the condition of 20 grids per minimum wavelength at the used maximum frequency of $1.0 \mathrm{~Hz}$, leading to sufficiently stable calculations (e.g., Bohlen and Saenger 2006). We finally plotted ACFs constructed by synthetic waveforms as a function of polarization direction and evaluated the differential

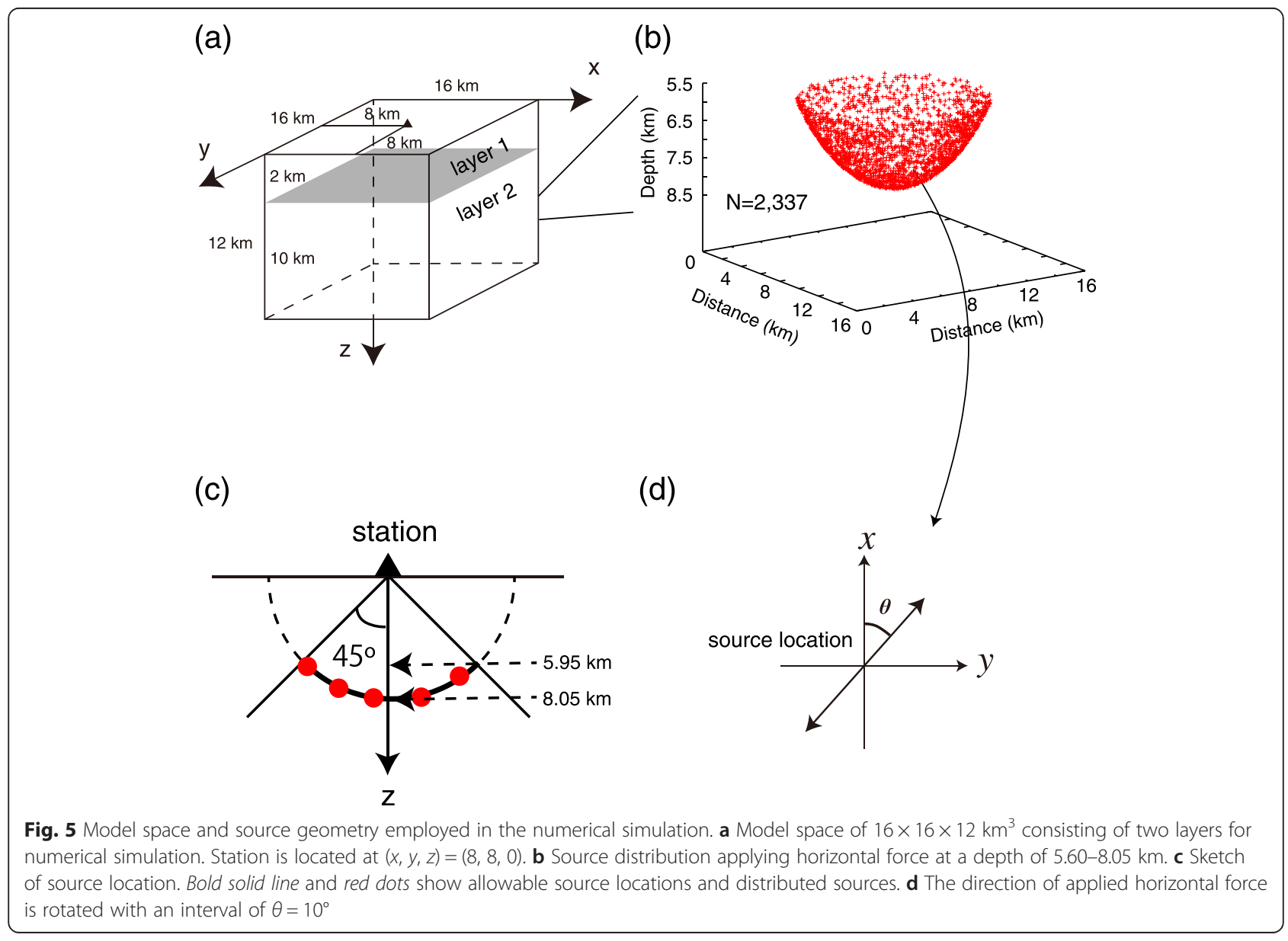


travel times of $S$ reflections for the aforementioned three cases.

Prior to examining the aforementioned source distribution, we first confirmed the travel time of $S$ reflections from one source located at $(x, y, z)=(8,8,8)$ in the model space containing two isotropic layers with a horizontal interface at a depth of $2 \mathrm{~km}$ (Fig. 6a). This velocity model is also examined in the following case (case 1). As a

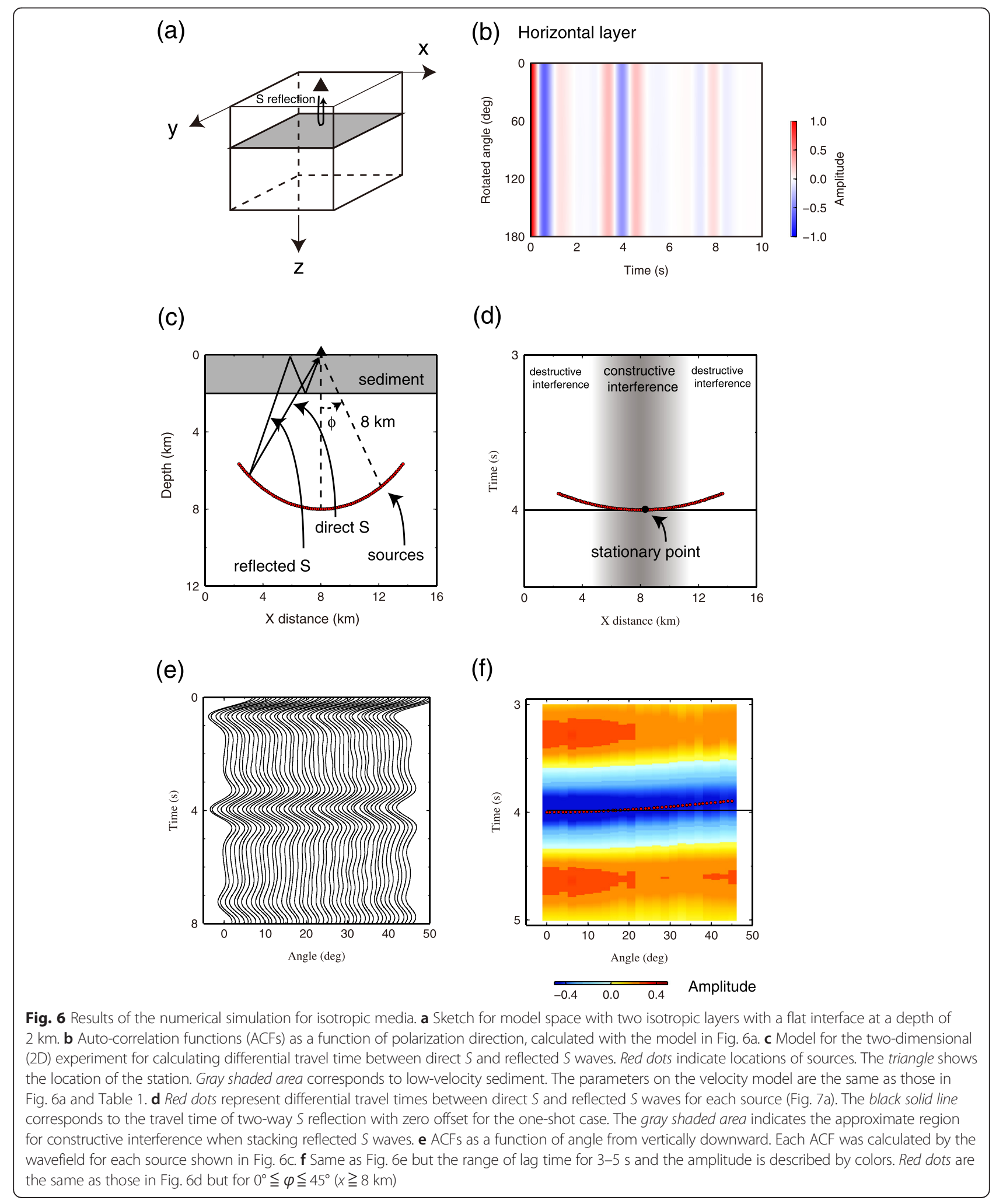


result, we obtained a lag time of $3.982 \mathrm{~s}(0.001 \mathrm{~s})$ for the vertically propagating $S$ reflection with zero offset.

Case 1: Fig. 6b shows the calculated ACFs as a function of polarization direction with the model shown in Fig. 6a. The $S$ reflection is emerged in the ACFs at a lag time of $3.950 \mathrm{~s}$ irrespective of the polarization direction and arrived faster than that of the one-source case. Although we further examined five calculations by randomly changing the source distribution, which satisfies the aforementioned location condition, all results on the lag times of $S$ reflection were $3.950 \mathrm{~s}(0.001 \mathrm{~s})$, implying that we can obtain stable results on the two-way travel time. In the velocity model with low and high velocities for the top and bottom layers, respectively, the travel time of $S$ reflections constructed from interferometry would depend mainly on the following three conditions: differential travel times between direct $S$ and reflected $S$ waves, amplitude of reflected $S$ waves, and wave duration. Hereafter, we distinguish the term "S reflection," which means the primary $S$ wave reflection between the seafloor and basement constructed by the interferometry (Fig. 6a), with the term "reflected $S$ wave," as coming from one source (Fig. 6c). According to the idea of a stationary point (Snieder 2004), at which the gradient of the travel time curve of a phase with respect to the wave incidence angle is 0 , a vertically propagating $S$ reflection from interferometry is constructed by the enhancement of effects of reflected $S$ waves coming with small angles from vertically downward by constructive interference and reduction of those with other incident angles by destructive interference. These interferences produce a vertically downgoing $S$ wave from the surface and its upgoing reflection from the horizontal interface.

The range of the wave incidence angle to the constructive and destructive interferences was determined by the aforementioned three conditions. For instance, Fig. 6c shows a $2 \mathrm{D}$ case for evenly distributed sources within a two-layered structure. The physical parameters of the velocity model are the same as those in Fig. 6a and Table 1. The sources are located within an angle range of $-45^{\circ} \leqq \phi \leqq 45^{\circ}$ and within a distance from the station of $8 \mathrm{~km}$ (Fig. 6c). The measurement of differential travel times between direct $S$ and reflected $S$ waves is displayed in Fig. 6d. The gradient of the differential travel time curve with respect to wave incidence angle is small around the stationary point. This implies that vertically propagating $S$ reverberations can be easily dominated at the top layer with a low velocity by various incident waves because upgoing waves with various slownesses at the bottom layer produce waves with near vertical incidence within the top layer. It is considered that such waves and their reflections, i.e., reverberations, are dominant within marine sediments. However, at the same time, this indicates that stacking reflected $S$ waves around the stationary point produce a slightly faster vertically propagating $S$ reflection than the theoretical travel time. The following two cases would construct an $S$ reflection with a travel time closer to the theoretical time: (1) the case of smaller velocity contrast at the top of the basement, which results in a larger gradient of differential travel time curves; and (2) the case of lower velocity in the top layer, which results in a smaller gradient of differential travel time. For the seafloor observation, the latter case would be realistic. This $2 \mathrm{D}$ experiment considered only the effect of differential travel time to waveform stacking. However, the amplitude of the reflected $S$ wave, or reflection coefficient, and its wave duration, or frequency component, would also contribute to the travel time of the $S$ reflection. Figure 6e, f shows individual ACFs for each source $\left(0^{\circ} \leqq \phi \leqq 45^{\circ}\right)$ shown in Fig. 6c. We applied a horizontal force at each source with a maximum frequency of $1.02 \mathrm{~Hz}$, which is the same as that in the 3D case. As shown in Fig. 6f, the $S$ reflection peak around a lag time of $4 \mathrm{~s}$ is slightly broad. When we stack these ACFs, the obtained travel time of $\mathrm{S}$ reflections would be deviated from the theoretical travel time. If we calculate the wavefield at higher frequency components, the $S$ reflection peaks emerging in each ACF will be sharper, resulting in a more accurate travel time of $S$ reflection in the stacked ACF.

In the case of the dipping interface $\left(5^{\circ}\right)$ within isotropic media (Fig. 7a), the two-way travel time of the $S$ reflection became $3.940-3.969 \mathrm{~s}(0.001 \mathrm{~s})$ with a travel time fluctuation of $0.029 \mathrm{~s}$ (Fig. 7b, d). This fluctuation is caused by the amplitude of the reflected $S$ wave and its wave duration. If we consider only differential travel time to waveform stacking, an $S$ reflection from a dipping interface should also be extracted in the ACFs at a lag time corresponding to the distance between the station and a point at which a perpendicular line from the station intersects to the dipping interface $\left(\mathrm{d}^{\prime}\right.$ in Fig. 7c). In addition, its travel time has no fluctuations and becomes smaller than that in the case of the horizontal interface because of $d>d^{\prime}$ in Fig. 7c. However, because such a dipping interface produces reflected $S$ waves with various amplitudes (reflection coefficients depending on the incident angle to the dipping interface) as a function of propagation direction for an incident angle, these waves unevenly contribute to construct an $S$ reflection around the stationary point, resulting in a slightly distorted waveform of the reflection. This is attributable to the travel time fluctuation in case of the dipping interface.

An important issue in the case of the dipping interface is whether this fluctuation affects $S$ anisotropy measurement. We determined that such an effect was quite small in the seafloor observation and that the differential travel times of $S$ reflections are caused only by $S$ anisotropy because of the following reason. $S$ waves coming from the bottom layer tend to propagate near normal to the dipping interface with decreasing $V s$ in the top layer. 


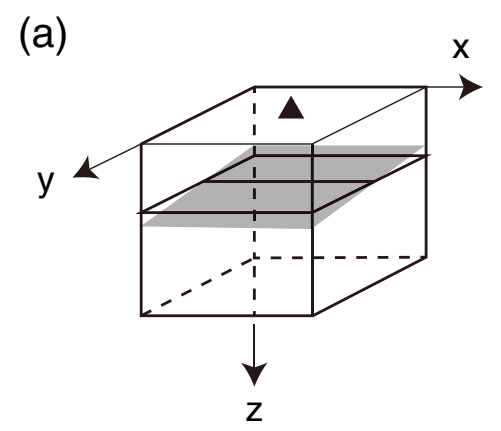

(c)
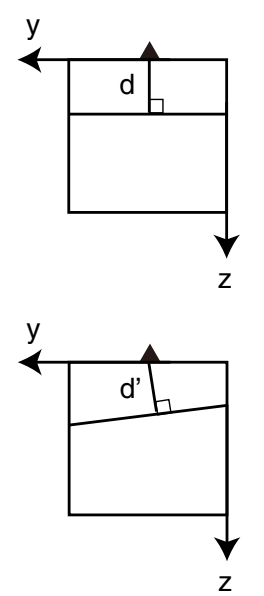

(b) Dipping layer (50)

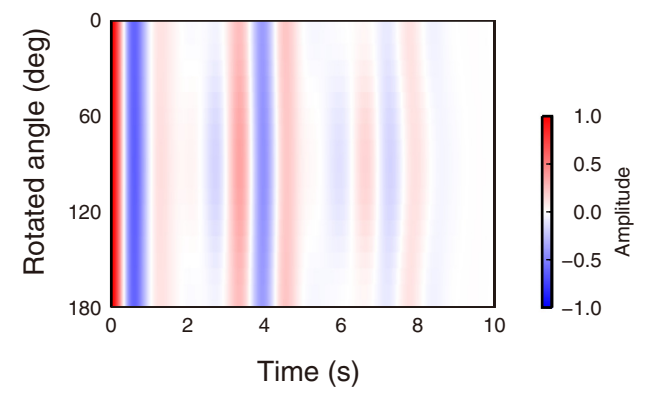

(d)

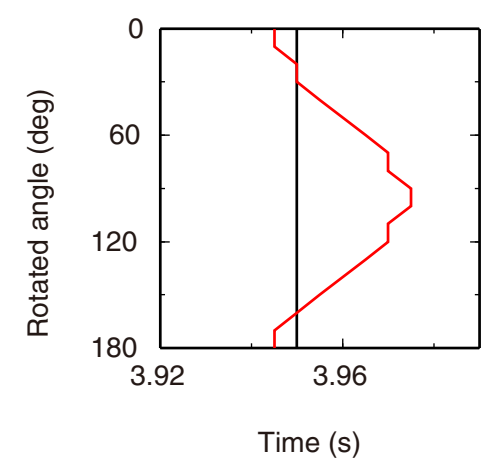

Fig. 7 a Same as Fig. 6a but for an interface with a dip angle of $5^{\circ}$ toward the $y$-direction. The label $d^{\prime}$ indicates the distance from the station to the dipping interface. $\mathbf{b}$ Same as Fig. $6 \mathrm{~b}$ but for the model in Fig. 7a. c The $y-z$ cross-sections of Figs. 6a and 7a. Labels $d$ and $d^{\prime}$ indicate the distance from station to interface. $\mathbf{d}$ Red and black lines indicate travel times of $\mathrm{S}$ reflection as a function of rotation angle for Figs. $6 \mathrm{~b}$ and $7 b$, respectively

As a result, the reflection points of the $S$ waves at the dipping interface are located around the stationary point, which produces reflected $S$ waves with similar two-way travel time and their amplitudes. Stacking these waves constructs $S$ reflections with significantly smaller travel time fluctuations with respect to the dipping interface. Indeed, we confirmed it by additional calculations. The velocity model was the same as the one in Fig. 7a but with a grid spacing of $0.04 \mathrm{~km}$ and a $V s$ of $0.9 \mathrm{~km} / \mathrm{s}$ at the top layer, which ensured good calculation accuracy with 22 grids per minimum wavelength. As a result, the two-way travel time of the $S$ reflection was 4.378-4. $391 \mathrm{~s}(0.001 \mathrm{~s})$ with a fluctuation of $0.013 \mathrm{~s}$, which is much smaller than that in the case of $V s=1.0 \mathrm{~km} / \mathrm{s}$ at the top layer. Furthermore, another calculation for a grid spacing of $0.025 \mathrm{~km}$ and $V s$ of $0.5 \mathrm{~km} / \mathrm{s}$ at the top layer with 20 grids per minimum wavelength resulted in $7.886-7.891 \mathrm{~s}(0.001 \mathrm{~s})$ of two-way travel time of $S$ reflection with a fluctuation of $0.005 \mathrm{~s}$. Because the $V s$ of marine sediment is significantly slower (e.g., $0.2 \mathrm{~km} / \mathrm{s}$ in Tonegawa et al. 2013), the dipping effect to the $S$ anisotropy measurement would be plausibly negligible.
Case 2: We set anisotropies of $d V p=0 \%$ and $d V s=-4 \%$, which are respectively equivalent to $B=0 \%$ and $E=-4 \%$ introduced by Park and Yu (1992) to the top layer of the model space with hexagonal symmetry (Fig. 8a). The symmetry axis was taken to be the $x$-direction, thereby producing a top layer with horizontal transverse isotropy (HTI) with a fast axis of the $y$-direction (Table 2); angles of $\eta$ and $\xi$ in Table 2 are measured from the $x$-axis and vertically downward, respectively (Fig. 8a). The degree of anisotropy in hexagonal symmetry can be converted to elastic constants (Park and Yu 1992; Nagaya et al. 2008). We assigned the same source distribution as that shown in Fig. 5b. The calculated ACFs show $S$ reflections at a lag time of 3.880$4.035 \mathrm{~s}$, which indicates that the travel times of the waves vary with the polarization direction of the $S$ wave (Fig. 8b). The differential travel time between fast and slow axes is $0.155 \mathrm{~s}$, which corresponds to a $V s$ anisotropy of $3.912 \%$ (dividing it by the averaged travel time of $3.963 \mathrm{~s}$ of $S$ reflection).

Case 3: The differential travel time of an $S$ reflection polarized in various directions could be affected by inhomogeneous source distribution. Herein, we preserved 


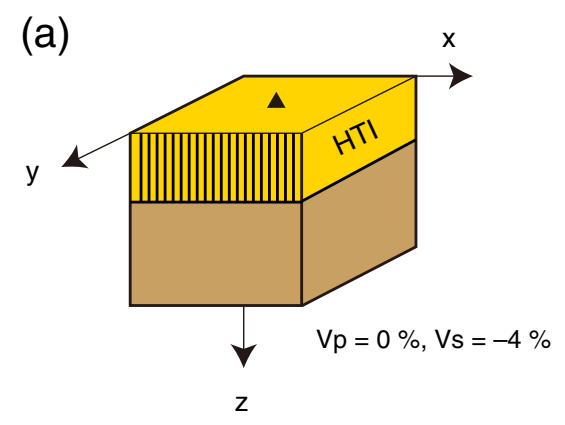

(c)

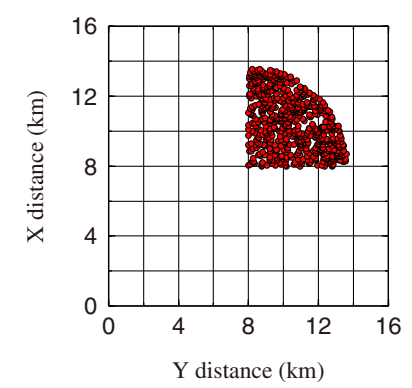

(b)

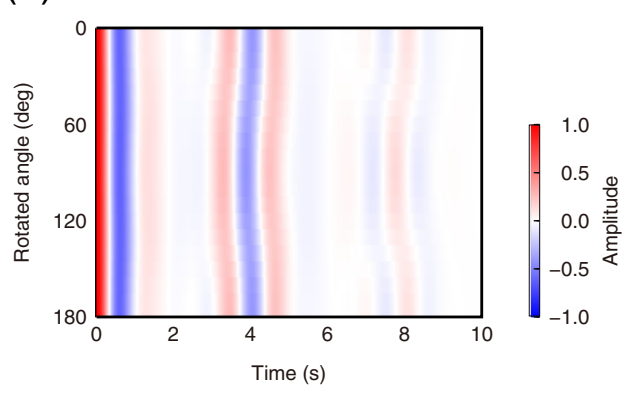

(d)

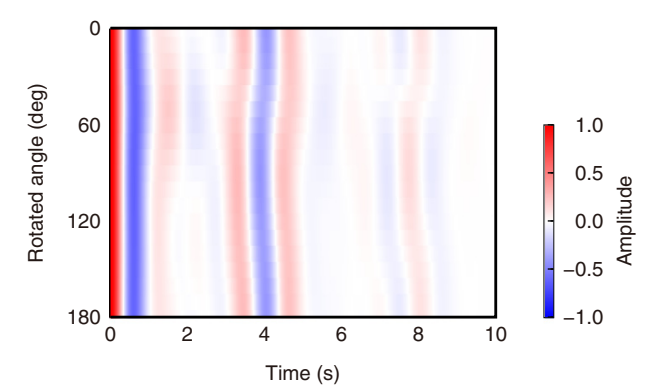

Fig. 8 Results of numerical simulation for anisotropic media. a Sketch for model space consisting of a horizontal transverse isotropy (HTI) top layer and an isotropic bottom layer with a flat interface at a depth of $2 \mathrm{~km}$. The degree of anisotropy is $d V p=0 \%$ and $d V s=-4 \%$. The source distribution is homogeneous. b Auto-correlation functions (ACFs) as a function of polarization direction, calculated with the model in Fig. 8a. c Map view of the source distribution used in the calculation of the ACFs shown in Fig. 8d. d Same as Fig. 8b but for the sources in Fig. $8 \mathrm{c}$

the sources at locations of $x \geqq 8 \mathrm{~km}$ and $y \geqq 8 \mathrm{~km}$ among those shown in Fig. 5b and discarded the other sources, which indicates that $S$ waves excited at these locations are coming from a back-azimuth range of $0-90^{\circ}$ (Fig. 8c). The synthetic ACF calculated in the model in Fig. 8a shows $S$ reflections at a lag time of $3.875-4.035$ s. A differential travel time of $0.160 \mathrm{~s}$ can be converted to an anisotropy of $4.040 \%$. Herein, although the obtained differential travel time was consistent with the case for evenly distributed sources, the behavior of the travel time fluctuation from unevenly distributed sources is slightly different relative to the case. The case of evenly distributed sources precisely represents the sinusoidal travel time curve of $S$ reflection, whereas that of unevenly distributed sources shows a distorted travel time curve from the sinusoidal variation (Fig. 8d), which may provide inaccurate directions of fast and slow axes and a slight degree of anisotropy. Obtaining accurate fast and slow polarization directions depends strongly on whether ambient noise sufficiently contains either $S$ waves with various

Table 2 Model parameters for anisotropy

\begin{tabular}{lcccc}
\hline & $d V p(\%)$ & $d V s(\%)$ & $\eta\left(^{\circ}\right)$ & $\xi\left(^{\circ}\right)$ \\
\hline Case 1 & 0 & 0 & 0 & 90 \\
Case 2 & 0 & -4 & 0 & 90 \\
Case 3 & 0 & -4 & 0 & 90 \\
\hline
\end{tabular}

slownesses for all azimuths or near-vertically propagating $S$ waves. In marine sediments, it appears that the latter condition is satisfied as subsequently discussed.

Summarizing the reflection extractions within a twolayered structure with isotropic media, the travel time of $S$ reflection from a horizontal interface could be slightly faster than the theoretical time, and the one from a dipping interface is also faster and has a travel time fluctuation. However, in the case of seafloor observation, due to low $V s$ within marine sediments, it is expected that the travel time of constructed $S$ reflection tends to be the accurate time and that the travel time fluctuation of the $S$ reflection due to the dipping interface tends to be small with respect to that of $S$ anisotropy. Moreover, the differential travel time of the $S$ reflection constructed from both evenly and unevenly distributed sources precisely shows $S$ anisotropy within the top layer.

\section{$S$ reflection from oceanic Moho}

The reason as to why $S$ reflections from the oceanic crust and mantle cannot be extracted from observed seismograms by the technique used in this study poses an interesting question. To investigate the reflection retrieval from interfaces below sediments, an effective method involves the investigation of the characteristics of the synthetic waveform/ACF calculated with a more realistic velocity model rather than the previous simulations. 
We carried out another 3D finite difference method by using standard staggered grids with calculation accuracies of second order in time and fourth order in space (Graves 1996). However, the top boundary of the solid part of the model space, i.e., solid/air boundary, has a calculation accuracy of second order in space to take into account the free surface effect (e.g., Okamoto and Takenaka 2005; Nakamura et al. 2012; Takemura and Yoshimoto 2014; Takemura et al. 2015). This calculation was conducted under the condition of using higher maximum frequency and lower minimum velocity than those used in the previous simulations. Involving such parameters with finite difference calculations generally requires a large-scale computation with finer grids to obtain stable solutions (e.g., Levander 1988). The used velocity model was based on that of a previous study (Shinohara et al. 2008). We added a sediment layer with a $V p$ of $1.6 \mathrm{~km} / \mathrm{s}$, a $V s$ of $0.2 \mathrm{~km} / \mathrm{s}$, and a thickness of $0.4 \mathrm{~km}$ (e.g., Kanazawa et al. 2001; Shinohara et al. 2008) above the velocity model (Fig. 8a). By using an empirical relation between the $V p$ and the density (Brocher 2005), we created a sediment-tomantle density profile (Fig. 9a). The calculation was performed in the velocity-stress scheme for isotropic media with a time step of $0.0002 \mathrm{~s}$. The model space $(x-y-z)$ was $12.288 \times 12.288 \times 15 \mathrm{~km}$ with a grid spacing of $0.008 \mathrm{~km}$. The quality factors for $P$ and $S$ wave attenuation were set

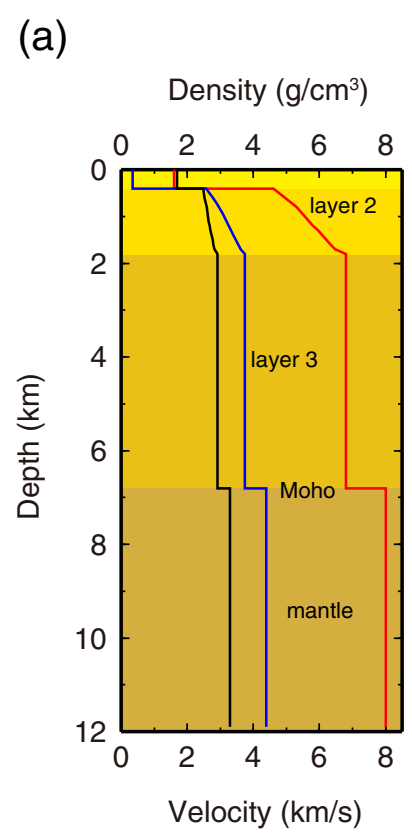

(b)
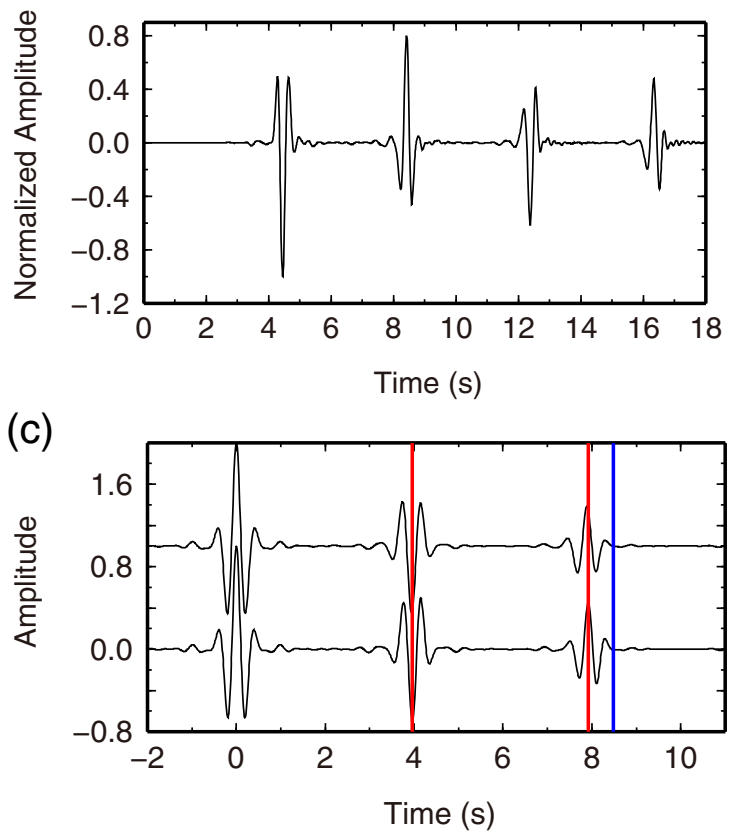

(d)

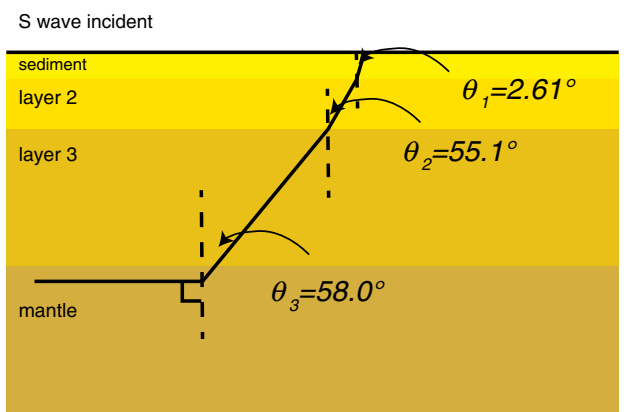

Fig. 9 Results of the numerical simulation for a realistic velocity model. a The employed velocity model created by referring to Shinohara et al. (2008). Red, blue, and black lines represent Vp, Vs, and density profile, respectively. The sediment thickness is $0.4 \mathrm{~km}$, and Vp and Vs are 1.6 and $0.2 \mathrm{~km} / \mathrm{s}$, respectively. The density is estimated based on $V_{p}$ of $1.6 \mathrm{~km} / \mathrm{s}$ through an empirical relation (Brocher 2005). b The synthetic waveform calculated with the velocity model in Fig. 9 a and for Qs $=300$. c The auto-correlation functions (ACFs) constructed with the synthetic waveform shown in Fig. 9b for $Q s=300$ (top) and $Q s=110$ (bottom). Red lines correspond to the theoretical two-way travel times of the first and second $S$ reflection from the top of the basement. The blue line indicates the theoretical two-way travel time of $\mathbf{S}$ reflection from the oceanic Moho. $\mathbf{d}$ The incident angles of $S$ wave to layer 3 , layer 2 , and sediment, in the case of horizontally propagating $S$ wave in the mantle 
to be $Q s=300$ and $Q p=2 Q s$, based on the method of Robertsson et al. (1994), within the entire model space. We adopted a single relaxation mechanism with a reference frequency of $f_{0}=2 \mathrm{~Hz}$, which provides peak $Q^{-1}$ values at this frequency. To perform this large-scale simulation effectively, we employed a parallel 3D simulation code based on a domain-partitioning procedure that utilizes a large number of processors with a message-passing interface (based on the work of Furumura and Chen 2004).

The station was located at the center on the free surface: $(x, y, z)=(6.144,6.144,0.008)$. We simultaneously applied horizontal forces with a Ricker wavelet at a maximum frequency of $3.125 \mathrm{~Hz}$ to 821 locations. Source locations were randomly determined from grids whose distance to the station was between 7.95 and $8.05 \mathrm{~km}$ and angled from vertically downward at the station of less than $30^{\circ}$, resulting in a depth range of sources of $6.87-8.05 \mathrm{~km}$. Herein, the direction of applied horizontal force and the observed horizontal component at the station are only one direction (the $y$-direction).

The simulation was conducted by using the Earth Simulator (ES2) supercomputer at the Japan Agency for Marine-Earth Science and Technology (JAMSTEC). A computer memory of 769 GB and a wall clock time of $2.1 \mathrm{~h}$ by parallel computing using 50 nodes ( 400 processors) of the supercomputer were required to evaluate seismic wave propagation of $18 \mathrm{~s}$ by 90,000 time-step calculations.

Figure 9b, c displays the calculated waveform and its ACF, respectively. The synthetic waveform shows a direct $S$ wave and three multiple reflections, which were constructed from the summation of 821 signals with one calculation (Fig. 9b). The ACF shows the first and second $S$ reflections with respective negative and positive polarities near the red lines that correspond to the theoretical zerooffset, two-way travel times of the reflections (Fig. 9c). The blue line indicates the theoretical arrival times of $S$ reflections from the oceanic Moho. However, such a phase could not be recognized in the synthetic ACF. Furthermore, we calculated ACF by changing to $Q s=110$ only at the marine sediment by referring to the result from Nolet and Dorman (1996). As a result, although the amplitude of the $S$ reflection from the top of the basement became smaller than that for $Q s=300$, the $S$ reflection from the oceanic Moho also could not be found in the ACF.

It appears that the reason for an absence of Moho reflections in the ACF is caused by a relatively weak impedance contrast at the Moho compared with the top of the basement. However, in addition to that, we consider that the absence is also caused by the difference of the wavefield feature between the sediment and crust. For instance, given a horizontally propagating $S$ wave in the mantle, i.e., an Sn wave, the incident angle to the marine sediment becomes $2.61^{\circ}$ with the velocity model shown in Fig. 9a (Fig. 9d). This means that upgoing $S$ waves with various slownesses in the mantle become nearvertically propagating $S$ waves within the sediment layer. Because the seafloor plays the role of the free surface for near-vertically propagating $S V$ and $S H$ waves, when the wavelength of $S$ wave is shorter than the thickness of the sediment layer, these waves are effectively trapped between the seafloor and the top of the basement that has a large impedance contrast. This would produce nearvertically propagating $S$ waves within the sediment. However, in the case of oceanic crust, the various slownesses of $S$ waves are presumably present within the layer due to relatively faster $V s$ than in sediment, indicating that the retrieval of vertically propagating $S$ wave is not effective by the correlation technique with a 1-day continuous record compared with the case in the sediment. This means that it may be possible to extract $S$ reflections from the oceanic Moho with more ambient noise record data, but whether the retrieval works well would also depend strongly on the impedance contrast at the boundary. In the case in which the amplitude of the reflected $S$ wave is weak, it would be obscured by reverberations in the sediment layer.

\section{Interpretation of sediment $S$ anisotropy}

As suggested by Tonegawa et al. (2013) based on anisotropic estimations in the northwestern Pacific region, $S$ anisotropy within marine sediments in the outer rise region would be caused by aligned cracks and normal faulting formed by the bending of the Pacific Plate (Fig. 10a). The observed anisotropic structure within marine sediments has been explained by the presence of aligned cracks (e.g., Haacke and Westbrook 2006; Haacke et al. 2009). In the outer rise region, because the plate is bending along the Japan and Kuril trenches, the tensional stresses are induced within the uppermost of the Pacific Plate nearly in the trench-normal direction. As a result, cracks and normal faulting form due to stresses within the marine sediment, and these fractures are aligned in the trench-parallel direction (Fig. 10c), causing $S$ anisotropy that has a trench-parallel fast axis. Such tensional stresses are also supported by earthquake mechanisms at shallower depths than $60 \mathrm{~km}$ (Fukuyama et al. 1998; Okada et al. 2004), which are mostly normal faulting with trench parallel strikes, around the outer rise region (Fig. 4a). The stress-induced anisotropy includes fractures within marine sediments due to the basement deformation associated with tensional stress, e.g., normal faulting within the basement or deeper (Fig. 10b). As discussed in the subsequent paragraphs, the expected trench-parallel fast axes were clearly observed along the Kuril Trench and along the northern part of the Japan Trench.

The fast polarization direction in box 1 in Fig. 4a, c shows the trench-parallel direction (red triangles in Fig. 4a, c), which reflects stress-induced cracks and fractures due to the basement deformation. In particular, the trench axis at this region coincides with the magnetic 
(a)

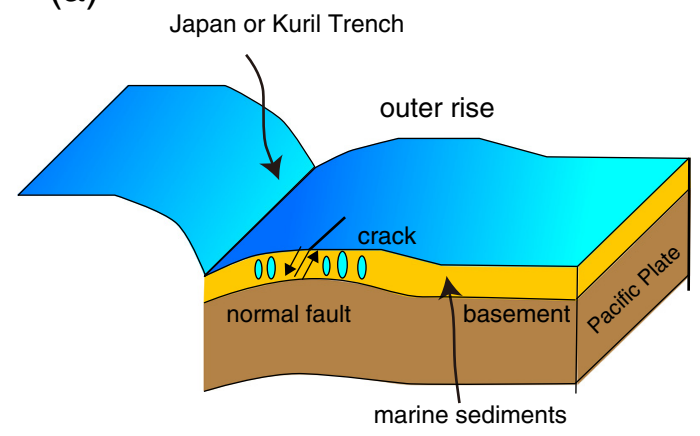

(b)

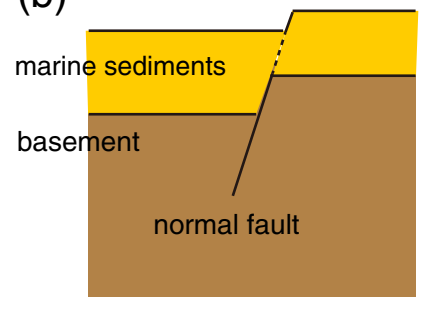

(c)

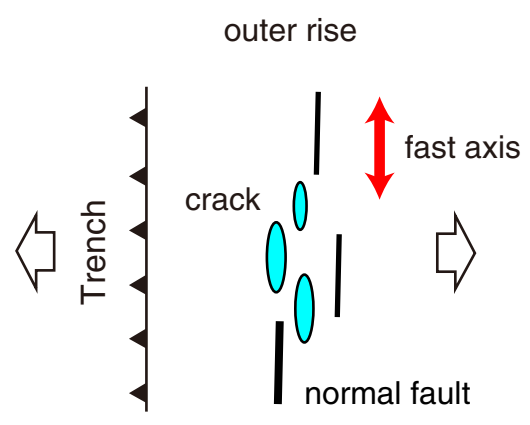

Fig. 10 Interpretation of the observed S anisotropy within the marine sediments. a Sketch showing cracks and normal faulting within sediments in the outer rise region. $\mathbf{b}$ Sketch showing fractures within sediments due to basement deformation. c Sketch showing cracks and faults in the outer rise region due to the tensional stress associated with the bending of the Pacific Plate

lineation direction (Nakanishi et al. 1989; Nakanishi 2011). The pre-existing fractures within the basement, which were formed at the creation of the Pacific Plate, gradually slide with the bending of the plate at the subduction zone, and the resulting displacement at the top of the basement produces the deformation of both sediments and the seafloor bathymetry above the basement. Because the region in this study has shifted southeasterly relative to the region where topographic features at the seafloor can often be observed, our study indicates that the development of these fractures begins landwards from the top of the outer rise region.

Compared with results in box 1 , the patterns of the fast axis in box 2 appear to be scattered (Fig. $4 d$, e). Because the bathymetry and magnetic lineation in the oceanic crust have been investigated in detail (Nakanishi et al. 1989; Nakanishi 2011), we divided box 2 into the northern and southern parts (Fig. 4e) and interpreted the direction of the fast axis with a relatively large degree of anisotropy in box 2 with such information. In the northern part of box 2, the fast direction indicated by the red triangles in Fig. 4d, e corresponds to the trench axis at the west of the OBS sites, which is consistent with that in box 1 . This reflects the trench-axis change from the Kuril Trench to Japan Trench. However, the fast axis oriented to the magnetic lineation could not be observed around this region, indicating fewer reactivations of the pre-existing fractures and high creations of newly formed fractures within the basement due to the bending of the plate.

In the southern part in box 2, we found that the fast axes at two OBS sites were oriented to $\mathrm{N} 30^{\circ} \mathrm{E}$ (denoted by the pale-blue triangles in Fig. 4e). It appears that this direction does not correspond to the direction of the trench axis at the west of the OBS sites. However, we consider that this direction reflects the trench axis south of $38^{\circ} \mathrm{N}$ (Fig. 4a). Nakanishi (2011) reported that landward- and oceanward-dipping escarpments with an orientation parallel to the trench axis south of $38^{\circ} \mathrm{N}$ have developed even at north of $38^{\circ} \mathrm{N}$. Because the region of the OBS sites has shifted easterly relative to the region where such topographical features can often be observed, it appears that the fast axes observed at the two OBS sites corresponds to both stress-induced cracks and fractures due to small amounts of basement deformation developing landwards from the top of the outer rise region. This result may also indicate that the direction of the tensional stress is rotated clockwise in the southern part of box 2 , according to the direction change of the trench axis occurring around $38^{\circ} \mathrm{N}$.

The direction of the fast axis at an additional two OBS sites is $\mathrm{N} 45^{\circ} \mathrm{E}$ (denoted by the blue triangles in Fig. 4e). 
Below the OBS sites, a NE-SW-trending lineation of the bathymetry can be recognized (Nakanishi 2011), and the direction almost coincides with the magnetic lineation pattern (Nakanishi et al. 1989; Nakanishi 2011). Such topography presumably reflects sediment deformation associated with fracture reactivations within the Pacific Plate formed at its creation, indicating that observed $S$ anisotropy within the sediment is possibly caused by the basement deformation along the magnetic lineation.

In summary of our observations, the direction of the fast axis around the Kuril Trench can be explained by the fractures associated with tensional stress, including stress-induced cracks (and normal faulting) and fractures associated with basement deformation. The anisotropic structure within marine sediments in the northern part of the Japan Trench is also formed by similar mechanisms to those in box 1. In the southern part, although we found two OBS sites that show the fast axis corresponding to the magnetic lineation, the pattern of the fast axis can be presumably explained by the anisotropic structure associated with the tensional stress of the plate bending. In addition, we found fast polarization directions shown by the orange triangles in Fig. 4, which cannot be simply explained by mechanisms associated with the tensional stress. It would be necessary that further possible mechanisms for creating $S$ anisotropy are explored through, e.g., MCS surveys and the bathymetry, in greater details.

\section{Conclusions}

We presented ACFs from ambient noise records observed by short-period OBSs that were deployed in the northwestern Pacific region. The ACFs clearly showed $S$ reflection from the top of the basement at 201 OBS sites. The degree of $S$ anisotropy was 1-2 \% around the top part of the outer rise region, and the fast polarization axis was taken to be in the trench-parallel direction there. Based on our observations in the northwestern Pacific, we derived the conclusion that $S$ anisotropy within marine sediments is produced by aligned fractures due to the tensional stresses that are associated with the bending of the Pacific Plate. The successful extractions of geographical patterns of $S$ anisotropy indicate that our technique used in this study is capable of retrieving alignments of fractures and fabric within marine sediments through anisotropic information. We also extensively carried out numerical simulations with simple velocity models, taking into account anisotropy. Most importantly, these revealed that ambient noise should contain incident waves coming from either near-below or at various azimuths and slownesses to the station for the retrieval of $S$ reflections containing accurate anisotropic information. It is predicted that the condition in which near-vertically propagating $S$ waves are dominant is satisfied with low $V s$ of marine sediments. However, another numerical simulation with a realistic velocity model also elucidated that this condition possibly hinders other reflections from interfaces below the basement.

\section{Abbreviations}

Vp: P-wave velocity; Vs: S wave velocity; ACFs: auto correlation functions; OBSs: ocean-bottom seismometers; HTI: horizontal transverse isotropy; MCS: multi channel seismic.

\section{Competing interests}

The authors declare that they have no competing interests.

\section{Authors' contributions}

TTo performed data processing and numerical simulations, in addition to preparin the first version of the manuscript. TTo, YF, GF, and ST contributed to the interpretations. ST conducted a more sophisticated numerical simulation by using a realistic velocity model. GF, $\Pi \mathrm{Ta}$, and KS designed seismic surveys and participated in data processing. All authors approved the final version of the manuscript.

\section{Acknowledgements}

We thank two anonymous reviewers for constructive comments that greatly improved the manuscript. The large-scale 3D simulation was conducted on the Earth Simulator at the Japan Agency for Marine-Earth Science and Technology (JAMSTEC) under the support of a joint research project between the Earthquake Research Institute, the University of Tokyo, and Center for Earth Information Science and Technology, titled "Seismic-wave propagation and strong ground motion in 3-D heterogeneous structure." Centroid moment tensor (CMT) solutions determined by using F-net records were provided by the National Research Institute for Earth Science and Disaster Prevention (NIED). TTo was funded by a Research Fellowship of the Japan Society for the Promotion of Science (JSPS) for Grants-in-Aid for Young Scientists (B: 15K17753).

\section{Author details}

${ }^{1}$ Research and Development Center for Earthquake and Tsunami, Japan Agency for Marine-Earth Science and Technology, 3173-25, Showa-machi, Kanazawa-ku, Yokohama 236-0001, Japan. ${ }^{2}$ Department of Material System Science, Graduate School of Nanobioscience, Yokohama City University, 22-2, Seto, Kanazawa-ku, Yokohama 236-0027, Japan. ${ }^{3}$ Present Address: Earthquake Research Institute, University of Tokyo, 1-1-1, Yayoi, 30 Bunkyo-ku, Tokyo 113-0032, Japan.

Received: 2 March 2015 Accepted: 31 August 2015

Published online: 17 September 2015

\section{References}

Bohlen T, Saenger EH (2006) Accuracy of heterogeneous staggered-grid finitedifference modeling of Rayleigh waves. Geophysics 71(4):T109-T115

Boué P, Poli P, Campillo M, Pedersen H, Briand X, Roux P (2013) Teleseismic correlations of ambient seismic noise for deep global imaging of the Earth. Geophys J Int 194:844-848

Brocher T (2005) Empirical relations between elastic wavespeeds and density in the Earth's crust. Bull Seismo Soc Am 95(6):2081-2092

Cadet JP, Kobayashi K, Aubouin J, Boulègue J, Deplus C, Dubois J, von Huene R, Jolivet L, Kanazawa T, Kasahara J, Koizumi K, Lallemand S, Nakamura Y, Pautot G, Suyehiro K, Tani S, Tokuyama H, Yamazaki T (1987) The Japan Trench and its juncture with the Kuril Trench cruise results of the Kaiko project, leg 3. Earth Planet Sci Lett 83:267-284

Campillo M, Paul A (2003) Long-range correlations in the diffuse seismic coda. Science 299:547-549

Draganov D, Wapenaar K, Thorbecke J (2004) Passive seismic imaging in the presence of white noise sources, The Leading Edge 23:889-892. doi:10.1029/ 2006GL028735

Draganov D, Wapenaar K, Mulder W, Singer J, Verdel A (2007) Retrieval of reflections from seismic background-noise measurements. Geophys Res Lett 34:L04305. doi:10.1029/2006GL028735

Draganov D, Campman X, Thorbecke J, Verdel A, Wapenaar K (2009) Reflection images from ambient seismic noise. Geophysics 74:A63-A67

Fujie G, Kodaira S, Yamashita M, Sato T, Takahashi T, Takahashi N (2013) Systematic changes in the incoming plate structure at the Kuril Trench. Geophys Res Lett 40:88-93. doi:10.1029/2012GL054340 
Fujiwara T, Hirano N, Abe N, Takizawa K (2007) Subsurface structure of the "petit-spot" volcanoes on the northwestern Pacific Plate. Geophys Res Lett 34:L13305. doi:10.1029/2007GL030439

Fukuyama E, Ishida M, Dreger DS, Kawai H (1998) Automated seismic moment tensor determination by using online broadband seismic waveforms. Zisin $51: 149-156$

Furumura T, Chen L (2004) Large scale parallel simulation and visualization of 3-D seismic wavefield using Earth simulator. Comput Model Eng Sci 6:153-168. doi:10.3970/cmes/2004.006.153

Graves RW (1996) Simulating seismic wave propagation in 3D elastic media using staggered-grid finite differences. Bull Seis Soc Am 86(4):1091-1106

Haacke RR, Westbrook GK (2006) A fast, robust method for detecting and characterizing azimuthal anisotropy with marine PS converted waves, and its application to the west Svalbard continental slope. Geophys J Int 167:1402-1412. doi:10.1111/j.1365-246X.2006.03186.x

Haacke RR, Westbrook GK, Peacock S (2009) Layer stripping of shear-wave splitting in marine PS waves. Geophys J Int 176:782-804. doi:10.1111/j.1365246X.2008.04060.x

Hudson JA (1981) Wave speeds and attenuation of elastic waves in material containing cracks. Geophys J Int 64:133-150

Isse T, Shiobara H, Tamura Y, Suetsugu D, Yoshizawa K, Sugioka H, Ito A Kanazawa T, Shinohara M, Mochizuki K, Araki E, Nakahigashi K, Kawakatsu H, Shito A, Fukao Y, Ishizuka O, Gill JB (2009) Seismic structure of the upper mantle beneath the Philippine Sea from seafloor and land observation: implications for mantle convection and magma genesis in the Izu-BoninMariana subduction zone. Earth Planet Sci Lett 278:107-119

Kanazawa T, Sager WW, Escutia C, Araki E, Arney JE, Carlson RL, Downey WS Einaudi F, Haggas SL, Hayasaka Y, Hirata K, Horner-Johnson BC, Mandernack KW, McCarthy FMG, Moberly R, Mochizuki M, Pedersen R, , Salimullah ARM, Shinohara M, Werner C (2001) Proc. ODP, Init. Repts. 191:College Station, TX (Ocean Drilling Program). doi:10.2973/odp.proc.ir.191.2001

Kawakatsu H, Kumar P, Takei Y, Shinohara M, Kanazawa T, Araki E, Suyehiro K (2009) Seismic evidence for sharp lithosphere-asthenosphere boundaries of oceanic plates. Science 324:499-502. doi:10.1126/science.1169499

Kodaira S, Fujie G, Yamashita M, Sato T, Takahashi T, Takahashi N (2014) Seismological evidence of mantle flow driving plate motions at a palaeo-spreading centre. Nature Geosci 7:371-375. doi:10.1038/NGEO2121

Kumar P, Kawakatsu H, Shinohara M, Kanazawa T, Araki E, Suyehiro K (2011) P and $S$ receiver function analysis of seafloor borehole broadband seismic data. J Geophys Res 116:B12308. doi:10.1029/2011JB008506

Levander AR (1988) Fourth-order finite-difference P-SV seismograms. Geophysics 53(11):1425-1436

Longuet-Higgins MS (1950) A theory of the origin of microseisms. Phil Trans R Soc A 243:1-35

Miyazawa M, Snieder R, Venkataraman A (2008) Application of seismic interferometry to extract $P$ - and $S$ - wave propagation and observation of shear-wave splitting from noise data at Cold Lake, Alberta, Canada. Geophysics 73(4):D35-D40

Nagaya M, Oda H, Akazawa H, Ishise M (2008) Receiver functions of seismic waves in layered anisotropic media: application to the estimate of seismic anisotropy. Bull Seis Soc Am 98(6):2990-3006. doi:10.1785/0120080130

Nakamura T, Takenaka H, Okamoto T, Kaneda Y (2012) FDM simulation of seismicwave propagation for an aftershock of the 2009 Suruga Bay Earthquake: effects of ocean-bottom topography and seawater layer. Bull Seis Soc Am 102(6):2420-2435

Nakanishi M (2011) Bending-related topographic structures of the subducting plate in the northwestern Pacific Ocean. In: Ogawa Y, Anma R, Dilek Y (ed) Modern Approaches in Solid Earth Sciences, 8, Springer Science+ Business Media B.V, Netherlands, doi:10.1007/978-90-481-8885-7_1.

Nakanishi M, Tamaki K, Kobayashi K (1989) Mesozoic magnetic anomaly lineations and seafloor spreading history of the northwestern pacific. J Geophys Res 94:15437-15462

Nakata N, Chang JP, Lawrence JF, Boué P (2015) Body-wave extraction and tomography at Long Beach, California, with ambient-noise interferometry. J Geophys Res 120(2):1159-1173. doi:10.1002/2015JB011870

Nolet G, Dorman LM (1996) Waveform analysis of Scholte modes in ocean sediment layers. Geophys J Int 125:385-396

Okada Y, Kasahara K, Hori S, Obara K, Sekiguchi S, Fujiwara H, Yamamoto A (2004) Recent progress of seismic observation networks in Japan: Hi-net, F-net, K-NET and KiK-net. Earth Planets Space 56:xV-xxvii
Okamoto T, Takenaka H (2005) Fluid-solid boundary implementation in the velocity-stress finite-difference method, Zisin 57:355-364 (in Japanese with English abstract)

Park J, Yu Y (1992) Anisotropy and coupled free oscillations: simplified models and surface waves observations. Geophys J Int 110:401-420

Poli P, Pedersen HA, Campillo M, POLENET/LAPNET Working Group (2012a) Emergence of body waves from cross-correlation of short period seismic noise. Geophys J Int 188:549-558

Poli P, Campillo M, Pedersen H, LAPNET Working Group (2012b) Body-wave imaging of Earth's mantle discontinuities from ambient seismic noise. Science 338:1063-1065

Robertsson J, Blanch JO, Symes WW (1994) Viscoelastic finite-difference modeling. Geophysics 59:1444-1456. doi:10.1190/1.1443701

Roux P, Sabra KG, Gerstoft P, Kuperman WA, Fehler MC (2005) P-waves from cross-correlation of seismic noise. Geophys Res Lett 32:L19303. doi:10.1029/ 2005GL023803

Ruigrok E, Campman X, Wapenaar K (2012) Basin delineation with a 40-hour passive seismic record. Bull Seis Soc Am 102(5):2165-2176

Ryberg T (2011) Body wave observations from cross-correlations of ambient seismic noise: a case study from the Karoo, RSA. Geophys Res Lett 38:L13311. doi:10.1029/2011GL047665

Saenger EH, Gold N, Shapiro SA (2000) Modeling the propagation of elastic waves using a modified finite-difference grid. Wave Motion 32:77-92

Shapiro NM, Campillo M (2004) Emergence of broadband Rayleigh waves from correlations of the ambient seismic noise. Geophys Res Lett. doi:10.1029/ 2004GL 019491

Shimamura H, Asada T, Suyehiro K, Yamada T, Inatani H (1983) Longshot experiments to study velocity anisotropy in the oceanic lithosphere of the northwestern Pacific. Phys Earth Planet Inter 31:348-362

Shinohara M, Fukano T, Kanazawa T, Araki E, Suyehiro K, Mochizuki M, Nakahigashi K, Yamada T, Mochizuki K (2008) Upper mantle and crustal seismic structure beneath the Northwestern Pacific Basin using a seafloor borehole broadband seismometer and ocean bottom seismometers. Phys Earth Planet Inter 170:95-106

Snieder R (2004) Extracting the Green's function from the correlation of coda waves: a derivation based on stationary phase. Phys Rev E 69:046610

Takemura S, Yoshimoto K (2014) Strong seismic wave scattering in the lowvelocity anomaly associated with subduction of oceanic plate. Geophys J Int 197:1016-1032. doi:10.1093/gji/ggu031

Takemura S, Furumura T, Maeda T (2015) Scattering of high-frequency seismic waves caused by irregular surface topography and small-scale velocity inhomogeneity. Geophys J Int 201:459-474. doi:10.1093/gji/ggv038

Thorbecke J, Draganov D (2011) Finite-difference modeling experiments for seismic interferometry. Geophysics 76(6):H1-H18. doi:10.1190/GEO02010-0039.1

Tibuleac IM, von Seggern D (2012) Crust-mantle boundary reflectors in Nevada from ambient seismic noise autocorrelations. Geophys J Int 189:493-500. doi:10.1111/j.1365-246X.2011.05336.x

Tonegawa T, Fukao Y, Nishida K, Sugioka H, Ito A (2013) A temporal change of shear wave anisotropy within the marine sedimentary layer associated with the 2011 Tohoku-Oki earthquake. J Geophys Res 118:607-615. doi:10.1002/ jgrb.50074

Tsuji T, Dvorkin J, Mavko G, Nakata N, Matsuoka T, Nakanishi A, Kodaira S, Nishizawa O (2011) Vp/Vs ratio and shear-wave splitting in the Nankai Trough seismogenic zone: insights into effective stress, pore pressure, and sediment consolidation. Geophysics 76(3):WA71-WA82

Zhan Z, Ni S, Helmberger DV, Clayton RW (2010) Retrieval of Moho-reflected shear wave arrivals from ambient seismic noise. Geophys J Int 182:408-420 